\title{
Bioremediation of contaminated marine sediments: examples of successful applications
}

\author{
L. Rocchetti, V. Fonti, F. Beolchini \& A. Dell'Anno \\ Università Politecnica delle Marche, DISVA, Italy
}

\begin{abstract}
Harbor sediments are often characterized by the presence of inorganic and organic contaminants, and this fact represents a relevant problem both when sediments are dredged and when they are left in the sea bottom. In this study we present the main results achieved by our research group in laboratory experiments addressed to marine sediment bioremediation. Dealing with sediments mainly contaminated with metals, several bioremediation strategies for metal biomobilization and biostabilization were tested. When the aim was to mobilize the metals from the sediments, Fe-reducing bacteria and the Fe/S oxidizing bacteria were used, and high extraction yields were obtained (>90\% for $\mathrm{Cu}, \mathrm{Cd}, \mathrm{Hg}$ and $\mathrm{Zn}$ ). Other experiments with the same purpose where carried out with sediments and $\mathrm{Fe}^{2+}$ to stimulate a mix of allochthonous acidophilic autotrophic and heterotrophic bacteria: $\mathrm{Ni}$ and $\mathrm{Zn}$ mobilization was enhanced (up to $>40 \%$ ), while other metals were more stable. The situation is more complex when sediments present a mixed contamination of hydrocarbons and metals. The experiments were based on the use of sulfate reducing bacteria and acetate under anaerobic conditions to stimulate hydrocarbon biodegradation. Although high hydrocarbon degradation were achieved ( $>40 \%)$, metals could be mobilized. Other treatments under anaerobic conditions with acetate and lactose lead to high hydrocarbon degradation (up to 80\%) and metal stabilization $(\mathrm{Cu}$ and $\mathrm{Zn})$. In sediment mainly contaminated with aliphatic and polycyclic aromatic hydrocarbons we tested the effect of a supply of inorganic nutrients and sand on hydrocarbon degradation $(>70 \%$ for aliphatic hydrocarbons and $40 \%$ for the aromatics). A semi-empirical kinetic model was fitted to the temporal changes of hydrocarbon concentrations to predict their degradation. Overall our data are of support for the improvement of the efficiency of bioremediation treatments.

Keywords: marine sediment, bioremediation, metals, hydrocarbons.
\end{abstract}




\section{Introduction}

Coastal marine sediments represent a deposit of contaminants that mainly originate from the anthropogenic activity. Harbors are one of the most contaminated coastal areas, where both organic contaminants, such as hydrocarbons, and inorganic contaminants, such as metals, are accumulated. In marine environment hydrocarbons and metals undergo biogeochemical transformations that influence their degradation, bioavailability and toxicity. Some of the modifications at the expense of these contaminants are driven by prokaryotic activity, which can change the physical-chemical parameters and the processes that naturally occur in the sediment, with consequences for hydrocarbon degradation and sorption, and metal speciation, partitioning and bioavailability [1-2]. Microorganisms are used for bioremediation of contaminated matrices, exploiting their capabilities of degrading contaminants, producing useful compounds and changing the mobility of metals [3-4]. Hydrocarbons are degraded by microorganisms under anaerobic and aerobic conditions, increasing the spectrum of bioremediation strategies that can be applied. One bioremediation strategy commonly used is biostimulation, which consists in the addition of nutrients or other compounds to enhance the biodegradation of organic contaminants. Another strategy is the bioaugmentation, which is based on the introduction in the contaminated system of allochthonous microorganisms with specific characteristics, such as the ability to degrade certain compounds or use metals during their metabolism. Examples of microorganisms that can be used for bioremediations are sulfate reducing bacteria, which under anaerobic conditions can degrade organic contaminants and stabilize metals in the sulfide fraction of the sediment. In aerobic acidic conditions autotrophic $\mathrm{Fe} / \mathrm{S}$ oxidizing bacteria may mobilize metals by the oxidation of metal-sulfide complexes and producing leaching agents [5-7].

This paper summarizes the main results of the studies by our research team about the bioremediation of marine contaminated sediments; these are shown here with a comprehensive look aiming at obtaining an overall picture of the state of the art of bioremediation strategies for contaminated sediments. For these reasons, the two main categories of the contamination (i.e., organic and inorganic contaminants) are here considered both as separated counterparts and as components intimately related. Indeed, the first approach was essential to achieve a better understanding of the mechanisms involved in bioremediation strategies studied, while the second one was useful to understand how the whole contamination is affected by remediation of the sediment by biological strategies.

\section{Materials and methods}

Laboratory scale bioremediation experiments were carried out with marine sediments sampled from different Italian ports. Considering the specific characteristics and kind of contamination of each sediment and the purpose of each study, different bioremediation strategies were applied. In the following part we briefly describe the experimental conditions. 
Sediment samples contaminated with metals were used for bioleaching experiments in the presence of autotrophic $\mathrm{Fe} / \mathrm{S}$ oxidizing bacteria (Acidithiobacillus ferrooxidans, At. thiooxidans and Leptospirillum ferrooxidans). Biological and chemical factors affecting bioleaching were investigated: the role of $\mathrm{Fe} / \mathrm{S}$ oxidizing bacteria, the effect of acidophilic heterotrophic Fe-reducing bacteria (Acidiphilium cryptum), different growth substrates $\left(\mathrm{Fe}^{2+}, \mathrm{S}^{0}\right.$ and glucose) and the concentration of the sediment $(20 \mathrm{~g} / \mathrm{L}$ and $100 \mathrm{~g} / \mathrm{L}$, dry sediment), working with samples coming from different ports [8-12]. Additional experiments were aimed at comparing bioleaching with chemical leaching strategies with chelating agents (citric acid and oxalic acid) that are naturally produced by living organisms (e.g. bacteria and fungi) or with sulfuric acid at low concentration.

Sediments contaminated with hydrocarbons and metals were used for anaerobic experiments aimed at metal stabilization and hydrocarbon degradation in the presence of acetate, lactose and an inoculum of sulfate reducing bacteria [13-14]. Other bioremediation experiments were carried out in aerobic (biostimulation with inorganic nutrients) and anaerobic conditions [15]. Biostimulation experiments with inorganic nutrients were carried out in aerobic conditions to degrade hydrocarbons, and also a two-step anaerobic-aerobic experiment was carried out [16]. In the anaerobic phase compost was added, and the effect on hydrocarbon degradation of acetate and sulfate reducing bacteria were investigated. A kinetic model was developed for experiments amended with inorganic nutrients and sandy sediments [17].

\section{Results and discussion}

\subsection{Marine sediments contaminated with metals}

An experimentation with sediment samples coming from the port of Ancona (20 g/L dry sediment) showed that Fe/S oxidizing bacteria were able to remove about $40-80 \%$ of $\mathrm{Cu}$ and $\mathrm{Ni}$ and $20-40 \%$ of $\mathrm{Zn}$ and $\mathrm{Cd}$ from the sediment [8]. When the sediment slurry was augmented with $\mathrm{Fe} / \mathrm{S}$ oxidizing bacteria and the Fe-reducing strain together the solubilization efficiencies increased significantly, till reaching about $90 \%$ of the total content of $\mathrm{Cu}, \mathrm{Cd}$ and $\mathrm{Zn} ; \mathrm{Cr}$ and $\mathrm{Pb}$, that in the absence of Fe-reducing bacteria were solubilized with efficiencies lower than $30 \%$, reached values round $50 \%$ of their total content. Anyway, further experimentations showed that these results were specific for the experimental conditions investigated. Indeed, experiments carried out with a sediment sample coming from a different seaport, but with the same sediment concentration, were characterized by very lower solubilization yields [10]. At the same way, additional experiments with the sediment from the port of Ancona but with a higher sediment concentration $(100 \mathrm{~g} / \mathrm{L}$, dry sediment) had a generally lower metal solubilization than with $20 \mathrm{~g} / \mathrm{L}$ of dry sediment [9].

A very recent study has pointed out that the solubilization of heavy metals from the sediment by bioleaching strategies is highly influenced by the geochemical properties of the sediment sample and by the characteristics of 
the contamination [12]. Thus, the development of eventual bioleaching remediation strategies should take into account the large differences between marine and freshwater sediments. In addition, different metals will have different solubilization yields, since the latter are influenced by metal-specific reactions and by their partitioning among the geochemical fractions of the sediments. Also the bacteria appeared affected by the physico-chemical constrains identified. In particular, their activity was favored by the presence of key substrata, like $\mathrm{Fe}^{2+}$, that $\mathrm{Fe} / \mathrm{S}$ bacteria transform in $\mathrm{Fe}^{3+}$, a highly leaching species.

The results of all these studied have supported the development of a conceptual model describing the biogeochemical interactions occurring during an hypothetical bioleaching treatment for contaminated sediment (Fig. 1; [12]). Since such model describes for the first time all the mechanisms potentially occurring we hope that it would be an useful tool towards the development of bioremediation technologies for contaminated sediments.

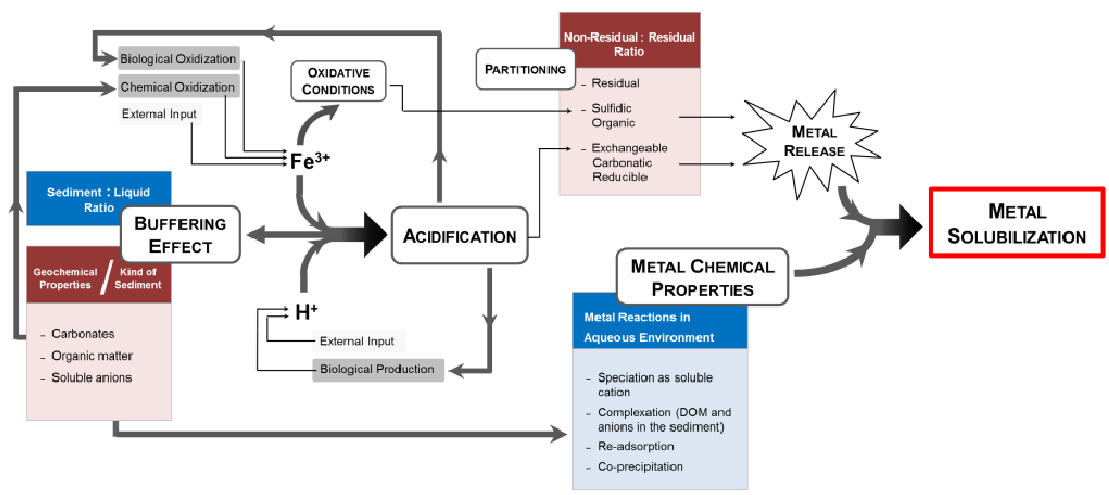

Figure 1: Conceptual model for metal bioleaching with contaminated sediments: A modification of the scheme published on Water Research [12].

A study of chemical leaching with organic acids or sulfuric acid at low concentration (to decrease the environmental impact) on seaport sediment samples (100 g/L) had $\mathrm{Zn}$, As, Cd and $\mathrm{Cr}$ solubilization yields comparable to those from bioleaching experiments [11]. This suggests that organic acids can be applied as chelating agents in sediment washing treatments but also that lowering the concentration of the sulfuric acid can be an additional option for treating the sediment with low environmental impact. This was confirmed by a Life-Cycle Analysis.

\subsection{Sediments contaminated with hydrocarbons and metals}

Hydrocarbon degradation efficiencies of about $50 \%$ of the initial amount were obtained during anaerobic biostimulation/bioaugmentation experiments. In particular, the addition of acetate as amendant to stimulate the autochthonous 
microbial community in the sediment had similar hydrocarbon degradation efficiencies than bio-augment the sediment with allochthonous consortia of sulfate reducing bacteria (Fig. 2; [13]). These treatment strategies had effect also on the inorganic component of the sediment contamination (i.e., heavy metals). $\mathrm{Zn}$ increased its mobility, moving towards the exchangeable/carbonatic fraction of the sediment. Other metals, on the contrary, were stabilized in the oxidizable fraction $(\mathrm{Cu}$ and $\mathrm{Pb})$.

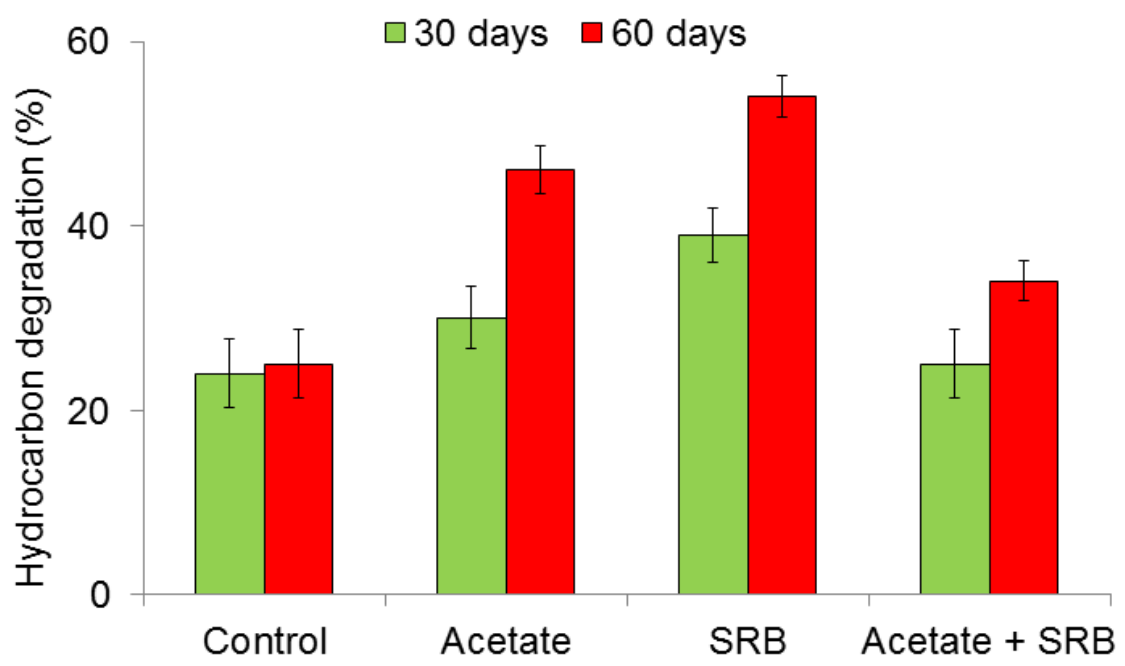

Figure 2: Percentage of hydrocarbon degradation in the bioremediation experiments with acetate and sulfate reducing bacteria (SRB; Dell'Anno et al. [13]).

A further study was then focused on the role of microbial assemblages in the sediment on the fate of hydrocarbons and metals [14]. When lactose was added to the experimental systems, high percentages of hydrocarbon degradation were observed (about 80\%) and Alphaproteobacteria, able to degrade hydrocarbons under anaerobic conditions, were widely present in the microbial assemblages [18]. Differently from what was expected, we found more sequences belonging to Methanosarcinales than Deltaproteobacteria and we hypothesized that, in the investigated conditions, methanogenesis was a very important metabolic function, more than sulfate reduction. In the presence of acetate or lactose, $\mathrm{Zn}$ and $\mathrm{Cu}$ were more stabilized in the residual fraction of the sediment. It seemed that an association between variations in metal mobility and Verrucomicrobia, Gammaproteobacteria and Euryarchaeota was present.

These results suggest that actions aimed at remove/reduce the contamination due to hydrocarbons has an effect also on the metals in the sediment. As a consequence, the fate of metals during eventual biostimulation actions (in-situ or ex-situ) should be taken into account, possibly by predictive tools. 
A study aimed at investigating the relationships between bacterial biodiversity and hydrocarbon degradation in marine contaminated sediments and with different redox conditions has provided additional elements in view of treatments aimed at hydrocarbon biodegradation [15]). The hydrocarbons were degraded both in aerobic (about 65\%) and anaerobic conditions (about 80\%) and the efficiency of their degradation was found to be related in a positive way with bacterial diversity, in both the redox conditions (Fig. 3). More diversified and more equally distributed microbial assemblages appears to offer a more effective degradation of hydrocarbons in marine contaminated sediments. Also the presence of inorganic nutrients during biostimulation actions appears to increase the biodegradation of hydrocarbons [16-17].

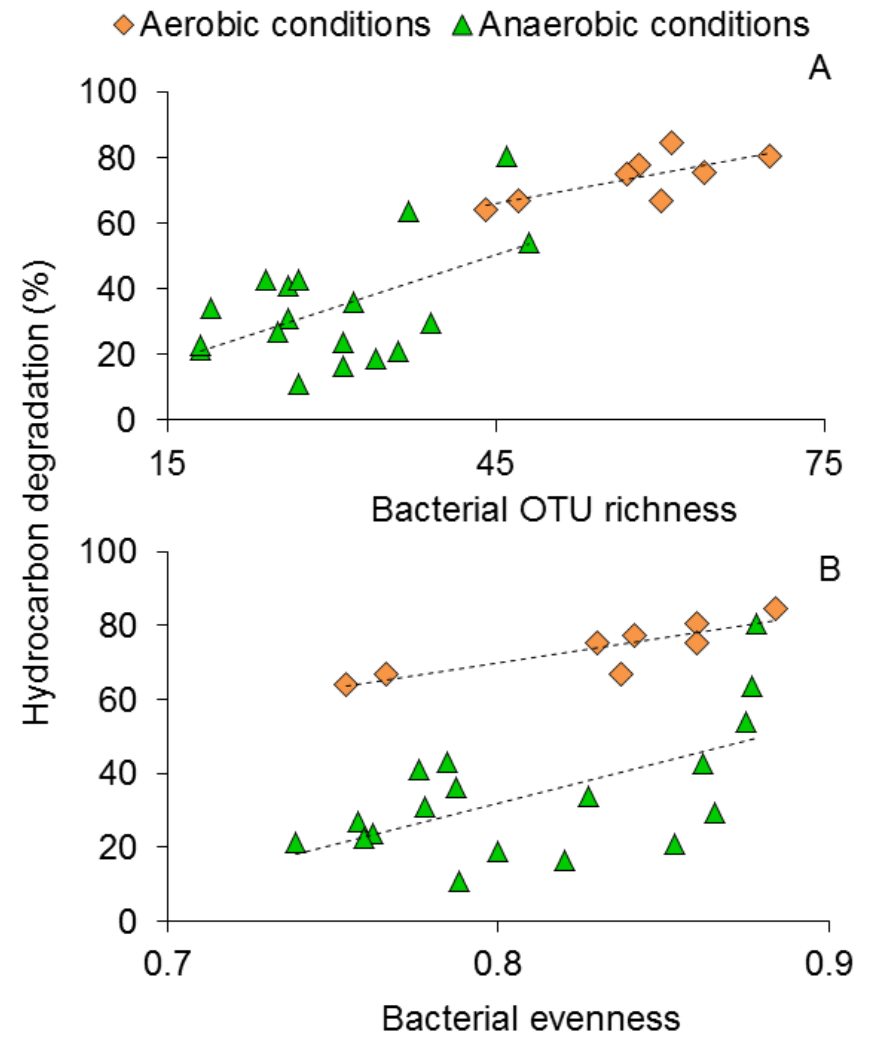

Figure 3: Relationships between hydrocarbon degradation and bacterial OTU richness (operational taxonomic unit, A) and evenness (B; Dell'Anno et al. [15]).

Experimental data from biostimulation/bioaugmentation experiments aimed at degrading hydrocarbons in contaminated sediments were used to evaluate the suitability of a simple semi-empirical kinetic model for the prevision of the timescales and performance of bioremediation experiments (Fig. 4). 


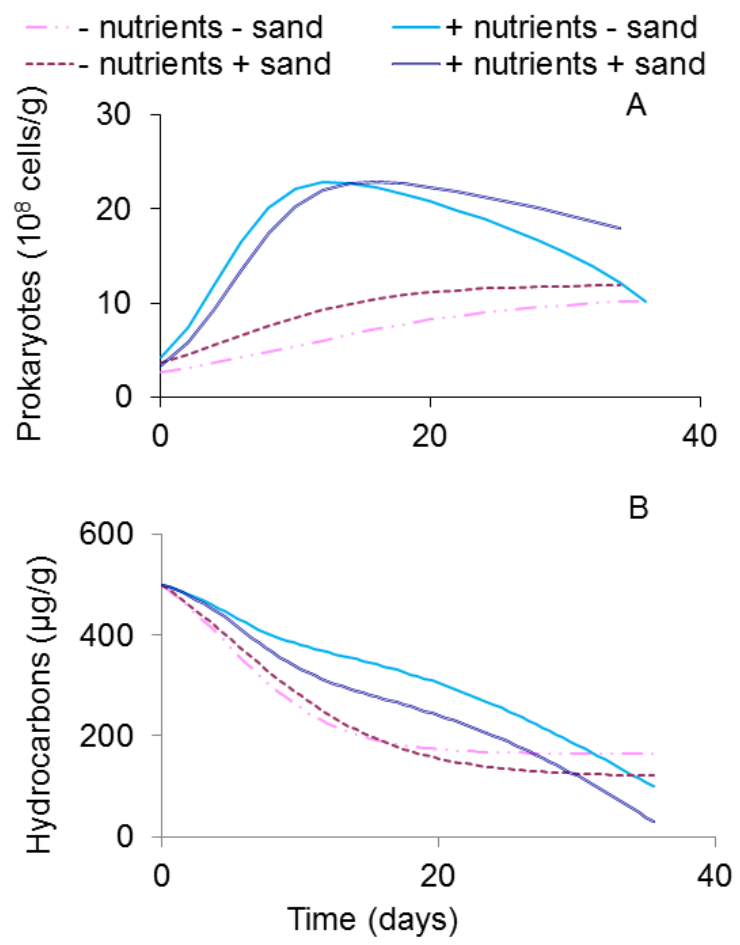

Figure 4: Prevision of the temporal changes of prokaryotic abundances (A) and hydrocarbon concentrations (B) [15].

\section{Conclusion}

Biostimulation and bioaugmentation strategies offer valid options for the degradation of hydrocarbons and the reclamation of metals from marine contaminated sediments. High performances of hydrocarbon biodegradation can be achieved and we observed that the biostimulation/bioaugmentation have effects also in the metal mobility. This aspect should be taken into account and metal contaminants should be carefully monitored, with respect to changes in their bioavailability.

Contrary to the majority of the studies in this field, our studies are aimed also at investigating the role of the microbial strains augmented or stimulated in the reclamation of metals and in the degradations of hydrocarbons. A particular attention is also paid to the effect of the geochemical properties of the sediment and of all the chemical species involved. We think that this "ecological" approach can offer new insights in the extremely challenging research field of the bioremediation of contaminated sediments. Indeed further research efforts should be aimed at implementing predictive tools that consider also the properties of the sediment. 


\section{References}

[1] Lloyd, R.J., Microbial reduction of metals and radionuclides. FEMS Microbiology Reviews 27, pp. 411-425, 2003.

[2] White, C., Sayer, J.A. \& Gadd, G.M., Microbial solubilisation and immobilization of toxic metals: key biogeochemical processes for treatment of contamination. FEMS Microbiology Reviews 20, pp. 503-516, 1997.

[3] Head, I.M. \& Swannell, R.P.J., Bioremediation of petroleum hydrocarbon contaminants in marine habitats. Current Opinion in Biotechnology 10, pp. 234-239, 1999.

[4] Head, I.M., Jones, D.M. \& Röling, W.F.M., Marine microorganisms make a meal of oil. Nature Reviews Microbiology 4, pp. 173-182, 2006.

[5] Rulkens, W.H., Grotenhuis, J.T.C. \& Tichy, R., Methods of cleaning contaminated soils and sediments. Heavy Metals, ed. W. Salomons, U. Förstner \& P. Mader, Springer: Berlin, pp. 151-191, 1995.

[6] Sand, W., Gehrke, T., Jozsa, P.G. \& Schippers, A., (Bio)chemistry of bacterial leaching - Direct vs. indirect bioleaching. Hydrometallurgy 59, pp. 159-175, 2001.

[7] Schippers, A. \& Sand, W., Bacterial leaching of metal sulfides proceeds by two indirect mechanisms via thiosulfate or via polysulfides and sulfur. Applied and Environmental Microbiology 65, pp. 319-321, 1999.

[8] Beolchini, F., Dell'Anno, A., De Propris, L., Ubaldini, S., Cerrone, F. \& Danovaro, R., Auto- and heterotrophic acidophilic bacteria interactions enhance the bioremediation efficiency of dredged sediment contaminated by heavy metals. Chemosphere, 74, pp. 1321-1326, 2009.

[9] Beolchini, F., Fonti, V., Dell'Anno, A., Rocchetti, L. \& Vegliò, F., Assessment of biotechnological strategies for the valorization of metal bearing wastes. Waste Management 32, pp. 949-956, 2012.

[10] Fonti, V., Dell'Anno, A. \& Beolchini, F., Mutualistic interactions during bioleaching of marine contaminated sediment. Chemical Engineering Transactions 32, pp. 979-984, 2013.

[11] Beolchini, F., Fonti, V., Rocchetti, L., Saraceni, G., Pietrangeli, B. \& Dell'Anno, A., Chemical and biological strategies for the mobilization of metal/metalloids in contaminated dredged sediments: experimental analysis and environmental impact assessment. Chemistry and Ecology 29, pp. 415-426, 2013.

[12] Fonti, V., Dell'Anno, A. \& Beolchini, F., Influence of biogeochemical interactions on metal bioleaching performance in contaminated marine sediment. Water Research 47, pp 5139-5152, 2013.

[13] Dell'Anno, A., Beolchini, F., Gabellini, M., Rocchetti, L., Pusceddu, A. \& Danovaro, R., Bioremediation of petroleum hydrocarbons in anoxic marine sediments: consequences on the speciation of heavy metals. Marine Pollution Bulletin 58, pp. 1808-1814, 2009.

[14] Rocchetti, L., Beolchini, F., Hallberg, K.B., Johnson, D.B., \& Dell'Anno A., Effects of prokaryotic diversity changes on hydrocarbon 
degradation rates and metal partitioning during bioremediation of contaminated anoxic marine sediments. Marine Pollution Bulletin 64, pp. 1688-1698, 2012.

[15] Dell'Anno, A., Beolchini, F., Rocchetti, L., Luna, G.M. \& Danovaro, R., High bacterial biodiversity increases degradation performance of hydrocarbons during bioremediation of contaminated marine sediments. Environmental Pollution 167, pp. 85-92, 2012.

[16] Rocchetti, L., Beolchini, F., Ciani, M. \& Dell'Anno A., Improvement of bioremediation performance for the degradation of petroleum hydrocarbons in contaminated sediments. Applied and Environmental Soil Science, Volume 2011, Article ID 319657, pp. 1-8, 2011.

[17] Beolchini, F., Rocchetti, L., Regoli, F. \& Dell'Anno, A., Bioremediation of marine sediments contaminated by hydrocarbons: experimental analysis and kinetic modeling. Journal of Hazardous Materials 182, pp. 403-407, 2010.

[18] Widdel, F. \& Rabus, R., Anaerobic biodegradation of saturated and aromatic hydrocarbons. Current Opinion in Biotechnology 12, pp. 259-276, 2001. 